\title{
Congenital Chylous Ascites and Lymphedema in Down's Syndrome: Correspondence
}

\author{
Jaya Agarwal
}

Received: 12 December 2012 / Accepted: 20 February 2013 /Published online: 6 June 2013

(C) Dr. K C Chaudhuri Foundation 2013

To the Editor: I read with interest the article on "Congenital chylous ascites and lymphedema in Down's syndrome" published in Nov. 2012 issue [1]. However I would like to make some comments on the management of the given case. Association of Down syndrome with primary chylous ascites has been well documented in literature with previous published case reports [2, 3]. Though authors mention investigation details to prove it to be chylous ascites but thorough evaluation to look into etiology of chylous ascites is missed. Primary chylous ascites is uncommon and is due toinadequate lymphatic drainage from the intestine that resultsfrom maldevelopment of the intra-abdominal lymphaticsystem [4]. Hence to label a given case as primary chylous ascites andto distinguish it from primary intestinal lymphangiectasia one needs to assess lymphatic system with either lymphoscintigraphy or lymphangiography and perform small bowel evaluation by upper gastrointestinal endoscopy with duodenal biopsy [5]. In few studies surgical exploration has also been resorted to search and treat abdominal and retroperitoneal chylous leaks and exeresis of lymphodysplastic tissues where initial investigation did not yield the site of leak or were refractory to medical treatment in such cases [6, 7]. It would have been appreciated if authors had also mentioned if at the last follow up of the child at 6 mo serum albumin was normalised or not and whether any albumin infusions were required while managing the case.

\section{References}

1. Bhattacharya S, Das NK, Chatterjee A. Congenital chylous ascites and lymphedema in Down's syndrome. Indian J Pediatr. 2012;79:1532.

2. Alliët P, Young C, Lebenthal E. Chylous ascites: Total parenteral nutrition as primary therapeutic modality. Eur J Pediatr. 1992;151:213-4.

3. Ochiai M, Hikino S, Nakayama H, Ohga S, Taguchi T, Hara T. Nonimmune hydrops fetalis due to generalized lymphatic dysplasia in an infant with Robertsonian trisomy 21. Am J Perinatol. 2006;23:63-6.

4. Chye NW, Lim CT, van der Heuvel M. Neonatal chylous ascites: Report of three cases and review of the literature. Pediatr Surg Int. 1997;12:296-8.

5. Bellini C, Boccardo F, Campisi C, et al. Lymphatic dysplasias in newborns and children: The role of lymphoscintigraphy. J Pediatr. 2008;152:587-9.

6. Campisi C, Bellini C, Eretta C, et al. Diagnosis and management of primary chylous ascites. J Vasc Surg. 2006;43:1244-8.

7. Cochran WJ, Klish WJ, Brown MR, Lyons JM, Curtis T. Chylous ascites in infants and children: A case report and literature review. J Pediatr Gastroenterol Nutr. 1985;4:668-73.

\section{J. Agarwal $(\bowtie)$}

Asian Institute of Gastroenterology,

Hyderabad, Andhra Pradesh 500082, India

e-mail: drjaya.agarwal@gmail.com 